\title{
The outcomes of surgical ASD closure in the era of catheter ASD closure; experience of single institute
}

\author{
S Kubota ${ }^{{ }^{*}}$, T Hoashi ${ }^{2}$, K Kagisaki ${ }^{2}$, S Yazaki ${ }^{1}$, J Kobayashi ${ }^{1}$, I Shiraishi ${ }^{3}$, H Ichikawa $^{2}$ \\ From 23rd World Congress of the World Society of Cardio-Thoracic Surgeons \\ Split, Croatia. 12-15 September 2013
}

\section{Background}

There is still demand for surgical closure of secundum atrial septal defect (sASD) in spite of the wide-spread of Amplatzer Septal Occluder (ASO). We sought to investigate the outcome of surgical sASD closure after ASO was introduced in our institute to find the indication and its morbidity compared with ASO.

\section{Methods}

Between August 2005 and December 2012, 524 patients with ASD below 18 years old were enrolled in this study. ASO was performed in 328 and surgical closure was performed in 195 . The indication for surgery was insufficiency of BW $(<15 \mathrm{~kg})$ in 61 , morphological reason in 120 , attempted but failed ASO in 8 (including one emergency case) and AV valve regurgitation in 5.

\section{Results}

There was no mortality. Only one patient needed re-exploration for acute cardiac tamponade and four patients needed permanent pacemaker implantation. Eleven required blood transfusion (BTF) (5.6\%). Cerebral infarction was encountered in one patient.

The patient was divided into two groups according to the body weight less than (group A) or above (group B) $15 \mathrm{~kg}$.

In group A, surgery was performed through partial sternotomy with small incision $(5.2 \pm 1.2 \mathrm{~cm})$. The mean size of ASD was $20.6 \pm 8.4 \mathrm{~mm}$. Nine patients who weigh less than $9.0 \mathrm{~kg}$ required BFT. No other patients required BTF.
In group B, The mean size of the ASD was $22.6 \pm 8.4 \mathrm{~mm}$. Since 2009, partial sternotomy with limited skin incision $(6.3 \pm 1.5 \mathrm{~cm})$ was applied in most of the patients $(55$ out of 66). Two patients required BTF for decreased hematocrit during cardiopulmonary bypass.

\section{Conclusion}

Although the surgical closure of ASD is safe and mostly done without transfusion, post-operative cerebral infarction occurred in one out of 192 patients. The physicians must inform the advantage and disadvantage of both interventions carefully to patients and families before deciding the treatment option.

\section{Authors' details \\ ${ }^{1}$ Departments of Cardiovascular surgery, National Cerebral and Cardiovascular Center, Suita, Japan. 'Department of Pediatric Cardiac surgery, National Cerebral and Cardiovascular Center, Suita, Japan. ${ }^{3}$ Department of Pediatric Cardiology, National Cerebral and Cardiovascular Center, Suita, Japan.}

Published: 11 September 2013

doi:10.1186/1749-8090-8-S1-P141

Cite this article as: Kubota et al:: The outcomes of surgical ASD closure in the era of catheter ASD closure; experience of single institute. Journal of Cardiothoracic Surgery 2013 8(Suppl 1):P141.

\footnotetext{
* Correspondence: kubota.sayaka.hp@mail.ncvc.go.jp

${ }^{1}$ Departments of Cardiovascular surgery, National Cerebral and

Cardiovascular Center, Suita, Japan

Full list of author information is available at the end of the article
}

(c) 2013 Kubota et al; licensee BioMed Central Ltd. This is an Open Access article distributed under the terms of the Creative Commons Attribution License (http://creativecommons.org/licenses/by/2.0), which permits unrestricted use, distribution, and reproduction in any medium, provided the original work is properly cited. 